\section{The Author Reply: A Truly Unusual Vascular Overgrowth Syndrome}

Key words: overgrowth syndrome, Parkes Weber syndrome

(Inter Med 48: 495, 2009)

(DOI: 10.2169/internalmedicine.48.1914)

To the Editor Dr. Alomari gave us some valuable comments on the diagnosis of our patient recently reported (1). First, Dr. Alomari pointed out that the term "KlippelTrénaunay-Weber syndrome (KTWS)" is inaccurate. Klippel-Trénaunay syndrome (KTS) is the eponym applied to a condition of capillary-venous malformation associated with altered limb bulk and/or length. Cases of the condition were first reviewed by Klippel and Trénaunay in 1900 (2), who noted the combination of capillary nevus, varicosities, and hypertrophy of tissues and bones of the affected limb. The association of these findings with arteriovenous fistulae was described in 1907 by Parkes Weber (3), and therefore, the additional name "Weber" is sometimes added to describe those individuals who also have clinically significant arteriovenous malformations (AVMs) as a component of their KTS (KTWS). Certainly, KTS and Parkes Weber syndrome (PWS) are, strictly speaking, distinct disorders with different pathogenesis. Because our patient clearly presented with subcutaneous AVMs, we agree that our patient does not belong to KTS. Hence, we should have used "PWS", not KTWS, in this case report.

However, even if an appropriate diagnosis of our patient would be PWS, his clinical picture was also atypical due to the presence of porthepatic venous shunts and no limbhypertrophy. We believe that the intrahepatic shunts should be a part of his systemic capillary-artery-venous vascular malformations since those were multiple and complex, regardless of the lack of severe liver cirrhosis. The diagnosis of Cobb syndrome or congenital lipomatous overgrowth, vascular malformations, and epidermal nevi (CLOVE) syndrome may be unlikely in our patient due to the lack of scoliosis, skeletal abnormalities, and spinal involvement as Dr. Alomari described.

Overgrowth syndromes with vascular malformations are clinically and etiologically quite heterogeneous and incompletely defined. While we clinically reported our patient as "an unusual case of KTWS (PWS)" (1), it remains unknown whether or not the diagnosis we made is proper. A careful follow-up and further analysis of our patient is needed to answer this question.

Masahide Yazaki and Shu-ichi Ikeda

\title{
References
}

1. Yazaki M, Kaneko K, Tojo K, et al. An unusual case of KlippelTrénaunay-Weber syndrome presenting with portosystemic encephalopathy. Intern Med 47: 1621-1625, 2008.

2. Klippel M, Trénaunay P. Du naevus variqueux ostéohypertro- phique. Arch General Med Paris 3: 611-672, 1900 (in French).

3. Weber FP. Angioma formation in connection with hypertrophy of limbs and hemi-hypertrophy. Br J Dermatol 19: 231-235, 1907.

Department of Neurology, Shinshu University School of Medicine, Matsumoto

Received for publication December 2, 2008; Accepted for publication December 4, 2008

Correspondence to Dr. Masahide Yazaki, mayazaki@hsp.md.shinshu-u.ac.jp

(C) 2009 The Japanese Society of Internal Medicine Journal Website: http://www.naika.or.jp/imindex.html 